Relations industrielles

Industrial Relations

\title{
Pierre Laporte, Code du travail du Québec (législation, jurisprudence et doctrine)
}

\section{Rodrigue Blouin}

Volume 47, numéro 1, 1992

URI : https://id.erudit.org/iderudit/050751ar

DOI : https://doi.org/10.7202/050751ar

Aller au sommaire du numéro

Éditeur(s)

Département des relations industrielles de l'Université Laval

ISSN

0034-379X (imprimé)

1703-8138 (numérique)

Découvrir la revue

Citer ce compte rendu

Blouin, R. (1992). Compte rendu de [Pierre Laporte, Code du travail du Québec (législation, jurisprudence et doctrine)]. Relations industrielles / Industrial

Relations, 47(1), 161-162. https://doi.org/10.7202/050751ar

Tous droits réservés (C) Département des relations industrielles de l'Université Laval, 1992
Ce document est protégé par la loi sur le droit d'auteur. L'utilisation des services d'Érudit (y compris la reproduction) est assujettie à sa politique d'utilisation que vous pouvez consulter en ligne.

https://apropos.erudit.org/fr/usagers/politique-dutilisation/ 
economy and that a similar Canadian mix of economic and social policies, including further union restrictions will, in the end, work here.

Bruce Spencen

Athabasca University

Code du travall du Québec (législation, Jurisprudence et doctrine), $5^{e}$ édition, par Pierre Laporte, Montréal, Wilson \& Lafleur Ltée, 1991, 558 p., ISBN 2-89127-191-2

Cette $5^{e}$ édition a su demeurer fidèle au fil des années aux orientations premières des instruments de travail publiés dans la collection ALTER EGO dirigée par le professeur Hubert Reid. On y retrouve toujours en effet des informations qui permettent d'acquérir une connaissance globale de l'état du droit en vigueur enchâssé au Code du travail, ou encore d'actualiser son savoir. Outre l'intérêt certain qui en résulte pour le praticien, l'apport pour les fins de l'enseignement est évident.

Dégagée depuis quelque temps déjà d'annexes dont l'utilité avait été interrogée (voir Relations industrielles, vol. 42, no 2, 1987, p. 436), l'édition courante se consacre dorénavant exclusivement à son objet: le régime général des rapports collectifs du travail. L'auteur a néanmoins conservé l'annexe relative à la ajurisprudence sur le partage des compétences"; on y retrouve quelques renseignements sur le partage constitutionnel et sur les effets extraterritoriaux du Code.

L'ouvrage contient en un premier regroupement le texte de loi (Code du travail), ses règlements (dont le Règlement sur l'exercice du droit d'association), ainsi que les dispositions pertinentes de la Charte de la langue française. Les annotations jurisprudentielles et doctrinales sont concentrées dans une seconde partie et sont détaillées sous chacun des articles du Code.

L'auteur mentionne que le contenu est à jour au 1er janvier 1991. II n'y a cependant aucune indication sur les recueils jurisprudentiels recensés. La recherche effectuée par l'auteur et sa collaboratrice, Me Hélène Ouimet, porte sur les jugements des tribunaux supérieurs en application du Code, sur les décisions du Tribunal du travail et des arbitres de griefs. On peut se surprendre que les décisions de l'organisme spécialisé dans l'accréditation et l'exercice de la liberté syndicale, le Bureau du commissaire-général du travail, ne soient pas répertoriées; cependant, quelques décisions classiques des anciennes Commission des relations ouvrières (1944-1964) et Commission des relations du travail (1964-1969) sont rapportées. En fait les annotations privilégient les aspects institutionnels du Code du travail, dont la délimitation des compétences, pouvoirs et devoirs des organismes. Dans cette mesure on peut comprendre le choix de l'auteur puisque les principes émanent plus de l'organisme d'appel, le Tribunal du travail, que des commissaires du travail.

Le lecteur retrouve généralement sous chacun des articles une triple catégories de renseignements: de brefs résumés sur des causes pertinentes, des références globales à de la doctrine et, le cas échéant, des renvois à de la 
jurisprudence indiquée sous d'autres articles. L'ordre de présentation respecte, lorsqu'il y a plusieurs espèces, un certain ordre décroissant allant des questions plus générales à des points particuliers. Il y aurait avantage à préciser dans les notes aux lecteurs les critères de sélection retenus. La notion de «pertinence» est trop large.

Les résumés de jurisprudence sont le plus souvent présentés sous forme de succincts énoncés de principes de droit. Ils sont bien faits et surtout clairs. La qualité de la présentation permet au lecteur de se faire assez rapidement une vue d'ensemble, ou encore de retrouver l'espèce particulière susceptible de l'intéresser. Le renvoi à la doctrine complète avantageusement l'information.

Deux tables et un index affermissent la présentation. La table de la jurisprudence est une heureuse initiative. Plutôt qu'une simple table de la doctrine, certes fort utile, le lecteur accueillerait avec satisfaction une courte synthèse de contenu sous chacun des textes doctrinaux. L'index bien que court comprend les sujets courants.

Le Code du travail du Québec annoté demeure en définitive un bon ouvrage dont l'utilité première est de servir comme matière de support. II peut ainsi répondre adéquatement aussi bien aux besoins de la pratique que de l'enseignement.

Rodrigue Blouin

Université Laval

Las relaciones de trabajo en los noventa. Desaflos y propuestas (Les relations du travail dans les années 1990: défis et propositions, en espagnol), sous la direction de Héctor Lucena et Fernando Calero, Valencia, ILDIS, ART et Université de Carabobo, 1990, 266 p., ISBN 980-6077-24-5

C'est sous l'instigation de l'Institut latinoaméricain de recherches sociales, de l'Association des relations de travail et de la Faculté des sciences économiques et sociales de l'Université de Carabobo qu'eut lieu à Valencia, les 30 et 31 mars 1990, le second congrès vénézuélien des relations industrielles. Cette rencontre devait favoriser une réflexion sur l'avenir des relations industrielles pour les dix prochaines années. L'ouvrage Las relaciones de trabajo en los noventa regroupe la transcription des communications présentées à cette occasion.

Dans un premier texte, Héctor Lucena identifie les principaux bouleversements qui, récemment, perturbèrent le système de relations industrielles. Les défis que présente chacun de ces changements font l'objet des communications subséquentes. Ainsi, Oscar Hernández Alvarez discute de la concertation sociale comme d'une politique économique et sociale requérant le consensus entre l'État, les travailleurs et les employeurs afin de répondre efficacement à une crise. De 1958 au début des années 1980, la concertation sociale fut passablement aisée car c'était l'occasion pour les acteurs sociaux de se partager les bénéfices générés par le boom pétrolier. La situation économique engendrée par la crise de 1982 allait pourtant rendre la concertation beaucoup 